The Egyptian Journal of Hospital Medicine (October 2019) Vol. 77 (1), Page 4861-4865

\title{
Botulinum Toxin-A, Fexofenadine Hydrochloride, and Nasal Corticosteroid (Triamcinolone) Spray in Treatment of Allergic Rhinitis Ahmed Abdelfattah ${ }^{1 *}$ and Essam A. El-Moselhy ${ }^{2}$ \\ Departments of ${ }^{1}$ Otorhinolaryngology and ${ }^{2}$ Community Medicine, Faculty of Medicine, Al-Azhar University, Egypt \\ *Corresponding author: Ahmed Abdelfattah, E-Mail: ahmedfatah10@ hotmail.com
}

\begin{abstract}
Background: allergic rhinitis (AR) is a common health challenge and its prevalence is rising. Many medications were used for treatment.

Aim of the work: to compare the effects of monotherapy with topical steroid, Botulinum Toxin-A (BTX-A) or Fexofenadine hydrochloride in treatment of AR.

Patients and Methods: one hundred and fifty patients with AR were included. They were divided into three equal groups; the first treated with a single dose intranasal injection of BTX-A, the second treated with Fexofenadine (once/day), and the third treated with intranasal steroid spray (Triamcinolone, once/day). All patients were evaluated before treatment for nasal symptoms and each symptom was scored by severity. In addition, patients were administered the rhinoconjunctivitis quality of life (RQoL) questionnaire. All patients were followed-up each two weeks till the end of the third month and data was evaluated in each visit.
\end{abstract}

Results: at baseline, groups were comparable regarding symptom severity and quality of life (QoL). At 2 weeks, all groups showed improvement in symptom severity and QoL. Regarding symptom severity, the lower was Triamcinolone followed by Fexofenadine and then BTX-A group, but QoL was significantly improvement in BTX-A, Fexofenadine and Triamcinolone respectively. At the end, there was significant reduction of symptom severity scores for obstruction, rhinorrhea, sneezing, itching, eye irritation, total nasal symptoms' score (TNSS) and QoL scores.

Conclusion: BTX-A may be a suitable alternative therapy for AR treatment. Otherwise, the treatment with second generation antihistamine or corticosteroids is effective.

Keywords: Allergic rhinitis, Botulinum toxin-A, Fexofenadine, Triamcinolone, Severity, Quality of life.

\section{INTRODUCTION}

Allergic rhinitis (AR) affects up to $20 \%$ of the population with increasing prevalence. It is a disease triggered by IgE-dependent chronic allergic inflammation of nasal mucous membranes in response to environmental allergens ${ }^{(\mathbf{1})}$.

The nasal triad symptoms of allergic rhinitis are paroxysmal and repetitive sneezing, rhinorrhea, and obstructed nose. AR could be divided into continuous or intermittent (according to duration of symptoms) and perennial or seasonal (according to the difference of allergens $)^{(2)}$. The number of patients with $\mathrm{AR}$ is estimated to be more than 500 million all over the world and 150 million in the Asia-Pacific region ${ }^{(\mathbf{3})}$.

The most common perennial allergens are dust mites $^{(4)}$. These allergens leading to release of mediators from immune cells of allergic inflammation including mast cells and eosinophils causing vasodilatation, hypersecretion, and inflammatory edema in the nasal mucosa. Symptoms include rhinorrhea, sneezing, itching, and nasal obstruction. It leads to significant impact in quality of life (QoL), mental, and psychomotor performance compared to the healthy people and also affects school learning achievement especially in adolescent age group ${ }^{(5)}$. Nasal obstruction secondary to vasodilatation and mucosal inflammatory edema is the major symptom of AR and nasal airway resistance is increased in these patients compared to that in nonallergic patients ${ }^{(6)}$. The main treatment of AR includes nasal topical corticosteroids. The efficacy of topical nasal corticosteroids depends on patient compliance. Maximum efficacy is usually apparent after 1-2 weeks. Oral antihistamines, although accepted as standard therapy for AR, have a lesser impact on nasal congestion and inflammation ${ }^{(7)}$.

In addition to "designer" antihistamines and topical nasal corticosteroids, attention has been directed to modulating the allergic reaction by inhibiting the formation of leukotrienes or blocking their effects. The original role of leukotrienes modifiers was in the treatment of asthma and polyposis, but recently they have been investigated as adjuncts to antihistaminic and/or corticosteroid therapy or as stand alone treatment for allergic rhinitis ${ }^{(\mathbf{8})}$.

\section{AIM OF THE WORK}

This study is aiming to compare the effects of monotherapy with topical steroid (Triamcinolone), Botulinum Toxin-A, and Fexofenadine hydrochloride in treatment of allergic rhinitis. 


\section{PATIENTS AND METHODS}

\section{Study type, site, and time:}

The present study is a prospective (follow-up) trial one, which conducted at Al-Azher University hospitals, through the period from March 2017 to June 2019.

\section{Study patients:}

The study included 150 patients with diagnosis of allergic rhinitis. They were selected from the outpatients' clinics of Otorhinolaryngology Department, Al-Azhar University hospitals. Patients were divided into three groups, each of them contained 50 AR patients and assigned to different treatment protocols. Group [1]: included patients who were treated with a single dose intranasal injection of BTX-A, Group [2]: included patient who were treated with Fexofenadine Hcl $120 \mathrm{mg}$ once daily, and Group [3]: included patients who were treated with intranasal steroid spray (Triamcinolone 55 $\mathrm{mcg} / \mathrm{dose}$ for each nostril once daily).

\section{Inclusion criteria:}

Patient with symptoms of AR longer than 2 years and no one had any oral or intranasal antihistamines and/or topical or systemic corticosteroids in the last 2 weeks.

\section{Exclusion criteria:}

Patient with one or more of the following criteria was excluded from the study: 1) lower airway disorders such as bronchiectasis, chronic obstructive pulmonary disease (COPD), etc.; 2) systemic disorders such as uncontrolled diabetes, cardiovascular disorders or hepatic disease; 3 ) pregnancy or nursing mothers; 4) ear, nose, throat or eye infection during the 2 weeks preceding the initial visit; 5) any condition likely to disturb absorption, distribution, metabolism, or excretion of the investigational drug.

\section{Patients' evaluation and examination:}

All the patients were evaluated before medical treatment, and every two weeks till the end of the third month after starting of the treatment. All patients underwent full history taking, complete ear, nose \& throat examination, and endoscopic examination. In addition, nasal symptoms' scoring was calculated: Patients were asked about their nasal symptoms including nasal obstruction, discharge, itching and sneezing. Each symptom was evaluated individually and the total nasal symptom score (TNSS) was calculated as the sum of four nasal symptoms. Symptom was scored as follows: zero for no symptoms, one (mild) for presentation of symptoms but not troublesome), two (moderate) symptom was frequently troublesome but not interfere with daily activity or sleep; and three (severe) symptoms that interfere with daily activity and sleep.

In addition, all patients were administered the rhinoconjunctivitis quality of life (RQoL) questionnaire, originally developed by Juniper $\boldsymbol{e t} \boldsymbol{a l} .{ }^{(9)}$. This questionnaire has 28-item questions related to the symptoms in seven domains (sleep, non-hay fever symptoms, practical problems, nasal problems, eye symptoms, activities, and emotional function). Patients were asked to express their responses on a 7-point scale $(0=$ no impairment, $6=$ severe impairment $)$. Overall mean score for all 28 questions was detected. High score corresponds to low QoL.

\section{Ethical and approval considerations:}

Full description of the procedures was explained to the patients and a free informed written consent was taken from each patient. In addition, patient's confidentiality was ascertained and patient's wright to withdrawal was guaranteed. In addition, an ethical approval from local Research and Ethics Committee of Al-Azhar Faculty of Medicine, Cairo, Egypt was obtained.

\section{Statistical analysis of data:}

The collected data were organized, tabulated and statistically analyzed using Statistical Package of Social Science (SPSS) computer package, version 20 (SPSS Inc. Chicago, USA). For qualitative data, frequency and percent distribution were calculated and for comparison between groups, Chi square $\left(\chi^{2}\right)$ test was used. For quantitative data, mean, minimum, maximum, and standard deviation (SD) were calculated. For comparison between two means; the independent samples t-test was used, for comparison between more than two means; the one-way analysis of variance (ANOVA; F test) was used, and for comparison between two periods of time for the same variable; the paired samples t-test was used. For interpretation of results, p-value $<0.05$ was considered significant.

\section{RESULTS}

In the present work, patients' ages ranged from 18 to 34 years, males represented $44.6 \%$ of all the studied populations and there was no statistically significant difference between the studied groups. In addition, there was no statistically significant difference between the studied groups as regard to personal history, family history of allergy, and clinical examination. In addition, disease duration ranged from 2 to 6 years and there was no statistically significant difference between the groups (Table 1). 
Table (1): Patient demographics, history, clinical examination and disease duration among the studied groups

\begin{tabular}{|c|c|c|c|c|c|c|}
\hline \multicolumn{2}{|c|}{ Variables } & $\overline{\text { BTX-A }}$ & Fexofenadine & Triamcinolone & $\overline{\mathbf{F}}$ & p-value \\
\hline \multicolumn{2}{|l|}{$\begin{array}{l}\text { Age (years): } \\
\text { Mean } \pm \text { SD: } \\
\text { Range: }\end{array}$} & $\begin{array}{c}26.70 \pm 2.38 \\
21-32\end{array}$ & $\begin{array}{c}26.48 \pm 2.90 \\
19-32\end{array}$ & $\begin{array}{c}27.12 \pm 3.01 \\
18-34\end{array}$ & $\begin{array}{c}0.68 \\
---\end{array}$ & 0.50(ns) \\
\hline \multirow{2}{*}{ Sex: } & Male & $24(48.0 \%)$ & $22(44.0 \%)$ & $21(42.0 \%)$ & \multirow{2}{*}{0.37} & \multirow{2}{*}{$0.82(\mathrm{~ns})$} \\
\hline & Female & $26(52.0 \%)$ & $28(56.0 \%)$ & $29(58.0 \%)$ & & \\
\hline \multirow{3}{*}{$\begin{array}{l}\text { Personal } \\
\text { History }\end{array}$} & Nasal operation & $12(24.0 \%)$ & $13(26.0 \%)$ & $11(22.0 \%)$ & 0.21 & $0.89(\mathrm{~ns})$ \\
\hline & Ear problems & $30(60.0 \%)$ & $21(42.0 \%)$ & $21(42.0 \%)$ & 4.32 & $0.12(\mathrm{~ns})$ \\
\hline & Throat allergy & $13(26.0 \%)$ & $12(24.0 \%)$ & $9(18.0 \%)$ & 0.98 & 0.61 (ns) \\
\hline \multicolumn{2}{|c|}{ Family history of allergy: Positive } & $12(24.0 \%)$ & $11(22.0 \%)$ & $11(22.0 \%)$ & 0.07 & $0.96(\mathrm{~ns})$ \\
\hline \multirow{2}{*}{\begin{tabular}{|l|} 
Clinical \\
examination
\end{tabular}} & Nasal polyp & $5(10.0 \%)$ & $5(10.0 \%)$ & $4(8.0 \%)$ & 0.15 & $0.92(\mathrm{~ns})$ \\
\hline & Hypertrophied turbinate & $40(80.0 \%)$ & $42(84.0 \%)$ & $41(82.0 \%)$ & 0.27 & $0.87(\mathrm{~ns})$ \\
\hline \multicolumn{2}{|c|}{$\begin{array}{l}\text { Disease duration (years): } \\
\text { Mean } \pm \mathrm{SD} \text { : } \\
\text { Range: }\end{array}$} & $\begin{array}{c}3.0 \pm 0.86 \\
2.0-5.0\end{array}$ & $\begin{array}{c}3.28 \pm 1.13 \\
2.0-6.0\end{array}$ & $\begin{array}{c}3.26 \pm 0.66 \\
2.0-5.0\end{array}$ & $\begin{array}{c}1.49 \\
---\end{array}$ & p.23(ns) \\
\hline
\end{tabular}

Ns: Statistically non-significant

Table (2): Comparison between groups as regard to TNSS and QoL at different follow-up visits

\begin{tabular}{|c|c|c|c|c|c|c|c|c|c|}
\hline \multirow{2}{*}{\multicolumn{2}{|c|}{ Variables }} & \multicolumn{2}{|c|}{ BTX-A } & \multicolumn{2}{|c|}{ Fexofenadine } & \multicolumn{2}{|c|}{ Triamcinolone } & \multirow{2}{*}{$\mathbf{F}$} & \multirow{2}{*}{$\begin{array}{c}\text { p- } \\
\text { value }\end{array}$} \\
\hline & & Mean & SD & Mean & SD & Mean & SD & & \\
\hline \multirow{7}{*}{$\begin{array}{l}\text { Total nasal } \\
\text { symptoms' } \\
\text { score } \\
\text { (TNSS) }\end{array}$} & Basal & 11.32 & 1.08 & 11.42 & 1.20 & 11.66 & 1.42 & 0.99 & $0.37(\mathrm{~ns})$ \\
\hline & At 2 weeks & 5.92 & 0.78 & 4.62 & 0.60 & 4.44 & 0.50 & 80.28 & $0.000^{*}$ \\
\hline & \begin{tabular}{|l|} 
At 4 weeks \\
\end{tabular} & 4.42 & 0.61 & 3.06 & 0.59 & 2.88 & 0.66 & 92.01 & $0.000^{*}$ \\
\hline & \begin{tabular}{|l|} 
At 6 weeks \\
\end{tabular} & 4.34 & 0.72 & 2.94 & 0.71 & 2.84 & 0.58 & 77.63 & $0.000^{*}$ \\
\hline & At 8 weeks & 4.20 & 0.73 & 2.90 & 0.71 & 2.74 & 0.60 & 68.84 & $0.000^{*}$ \\
\hline & \begin{tabular}{|l|} 
At 10 weeks \\
\end{tabular} & 4.04 & 0.78 & 2.70 & 0.79 & 3.20 & 2.79 & 7.62 & $0.0007 *$ \\
\hline & \begin{tabular}{|l|} 
At 12 weeks \\
\end{tabular} & 4.10 & 1.09 & 2.90 & 1.16 & 3.18 & 0.94 & 17.3 & $0.000 *$ \\
\hline \multicolumn{2}{|c|}{ Repeated ANOVA } & \multicolumn{2}{|c|}{$\mathbf{P}$-value $=0.000^{*}$} & \multicolumn{2}{|c|}{ P-value $=0.000^{*}$} & \multicolumn{2}{|c|}{ P-value $=0.000^{*}$} & --- & --- \\
\hline \multirow{7}{*}{$\begin{array}{c}\text { Quality of } \\
\text { life } \\
\text { (QoL) }\end{array}$} & Basal & 45.60 & 5.76 & 44.46 & 5.63 & 45.64 & 5.62 & 0.69 & 0.499 \\
\hline & \begin{tabular}{|l|} 
At 2 weeks \\
\end{tabular} & 22.64 & 3.42 & 23.06 & 3.65 & 24.70 & 4.40 & 4.0 & $0.02 *$ \\
\hline & At 4 weeks & 20.94 & 3.29 & 21.18 & 3.31 & 22.56 & 3.83 & 3.14 & $0.046^{*}$ \\
\hline & \begin{tabular}{|l|} 
At 6 weeks \\
\end{tabular} & 19.62 & 2.73 & 19.98 & 2.83 & 21.38 & 3.36 & 4.84 & $0.009^{*}$ \\
\hline & At 8 weeks & 17.84 & 2.49 & 17.96 & 2.81 & 19.90 & 3.33 & 7.96 & $0.0005^{*}$ \\
\hline & At 10 weeks & 16.48 & 2.47 & 16.74 & 2.71 & 18.18 & 2.97 & 5.64 & $0.004 *$ \\
\hline & At 12 weeks & 14.68 & 2.26 & 15.00 & 2.70 & 16.26 & 2.69 & 5.33 & $0.005^{*}$ \\
\hline \multicolumn{2}{|c|}{ Repeated ANOVA } & \multicolumn{2}{|c|}{$\mathbf{P}$-value $=0.000^{*}$} & \multicolumn{2}{|c|}{$\mathbf{P}$-value $=0.000^{*}$} & \multicolumn{2}{|c|}{$\mathbf{P}$-value $=0.000^{*}$} & --- & --- \\
\hline
\end{tabular}

*: Statistically significant difference

Before inclusion in the study, all groups were comparable as regard to TNSS and QoL scores. At 2 weeks after treatment, there was statistically significant difference between the groups as regard to TNSS, where the lower scores were registered in Triamcinolone group followed by Fexofenadine and finally BTX-A group. This situation continued from the second week to the end of follow-up period at 12 weeks after initiation of the treatment. Similarly, there was statistically significant difference between the studied groups as regard to QoL at 2 weeks and continued till the end of the follow-up visit at 12 weeks, but QoL score was significantly decreased in BTX-A group, followed by Fexofenadine and finally Triamcinolone group. In addition, in each group there was statistically significant progressive improvement of TNSS and QoL scores (table 2). 
ejhm.journals.ekb.eg

Table (3): Comparison of each symptom severity scoring and RQoL Questionnaire before and at the end of follow-up period

\begin{tabular}{|l|c|c|c|c|c|c|c|c|c|}
\hline \multirow{2}{*}{ Variables } & \multicolumn{4}{|c|}{ BTX-A } & \multicolumn{3}{c|}{ Fexofenadine } & \multicolumn{3}{c|}{ Triamcinolone } \\
\cline { 2 - 11 } & Basal & Final & $\begin{array}{c}\text { P- } \\
\text { value }\end{array}$ & Basal & Final & $\begin{array}{c}\text { P- } \\
\text { value }\end{array}$ & Basal & Final & $\begin{array}{c}\text { P- } \\
\text { value }\end{array}$ \\
\hline Obstruction & $2.32 \pm 0.55$ & $1.24 \pm 0.47$ & $0.000^{*}$ & $2.38 \pm 0.49$ & $0.78 \pm 0.61$ & $0.000^{*}$ & $2.36 \pm 0.52$ & $0.76 \pm 0.55$ & $0.000^{*}$ \\
\hline Rhinorrhea & $2.36 \pm 0.52$ & $0.94 \pm 0.61$ & $0.000^{*}$ & $2.36 \pm 0.56$ & $0.58 \pm 0.53$ & $0.000^{*}$ & $2.60 \pm 0.49$ & $0.74 \pm 0.44$ & $0.000^{*}$ \\
\hline Sneezing & $2.46 \pm 0.50$ & $0.48 \pm 0.57$ & $0.000^{*}$ & $2.48 \pm 0.50$ & $0.48 \pm 0.50$ & $0.000^{*}$ & $2.50 \pm 0.50$ & $0.52 \pm 0.50$ & $0.000^{*}$ \\
\hline Itching & $2.44 \pm 0.54$ & $1.08 \pm 0.34$ & $0.000^{*}$ & $2.58 \pm 0.49$ & $0.62 \pm 0.53$ & $0.000^{*}$ & $2.56 \pm 0.50$ & $0.76 \pm 0.43$ & $0.000^{*}$ \\
\hline Eye irritation & $1.74 \pm 0.52$ & $0.36 \pm 0.48$ & $0.000^{*}$ & $1.62 \pm 0.49$ & $0.44 \pm 0.54$ & $0.000^{*}$ & $1.64 \pm 0.48$ & $0.40 \pm 0.49$ & $0.000^{*}$ \\
\hline TNSS & $11.32 \pm 1.07$ & $4.10 \pm 1.09$ & $0.000^{*}$ & $11.42 \pm 1.19$ & $2.90 \pm 1.16$ & $0.000^{*}$ & $11.66 \pm 1.42$ & $3.18 \pm 0.94$ & $0.000^{*}$ \\
\hline RQoL & $45.60 \pm 5.76$ & $14.68 \pm 2.26$ & $0.000^{*}$ & $44.46 \pm 5.62$ & $15.0 \pm 2.69$ & $0.000^{*}$ & $45.64 \pm 5.61$ & $16.26 \pm 2.69$ & $0.000^{*}$ \\
\hline
\end{tabular}

*: Statistically significant difference, TNSS: Total nasal symptoms score, RQoL: Rhinocon quality of life

At the end of follow-up in each group, there was statistically significant decrease of symptom severity score of obstruction, rhinorrhea, sneezing, itching, eye irritation, total TNSS and RQoL scores (table $\mathbf{3}$ ).

\section{DISCUSSION}

Allergic rhinitis (AR) is an IgE-mediated disorder affecting nasal mucosa and typically presented after exposure to allergens such as pollen, house dust mites or animal hair. Treatment of such ailment includes the avoidance of exposure to unique allergens when possible, that is typically tough and unpractical. Hence, various medications were evolved to prevent or decrease the symptoms of AR. Those medications include antihistamines, corticosteroids, nasal decongestants, anticholinergics, and leukotriene receptor antagonists. Few of these drugs lead to complete alleviation of symptoms without complications. In addition, these drugs commonly require frequent administration once- or twice-daily for a pretty lengthy time period, hence deteriorating the QoL of the patients ${ }^{(\mathbf{1 0})}$.

Early in 1949, Burgen et al. $^{(\mathbf{1 1})}$ stated that Botulinum toxin type A (BTX-A) blocks signal transmission at the neuromuscular and neuro-glandular junctions, as it decreases acetylcholine secretion from presynaptic nerve endings. Rohrbach et al $^{(\mathbf{( 1 2 )}}$ mentioned that, BTX-A is widely used to manage various neuromuscular disease (e.g., strabismus, blepharospasm, achalasia, and facial spasm).

BTX-A has additionally been used in the field of cosmetics and the stoppage of gustatory sweating ${ }^{(\mathbf{1 3}, \mathbf{1 4})}$.

The present study was designed to compare the effects of monotherapy with topical steroid, Botulinum Toxin-A or Fexofenadine hydrochloride (Antihistamine) in treatment of allergic rhinitis mainly on TNSS and QoL. Results of the present study revealed that single injection of BTX-A was effective as daily use of corticosteroids and antihistamine in alleviation of symptoms of allergic rhinitis till the end of third months. Its outcomes on QoL is superior to corticosteroids and antihistamine.

Compared to results of the present work, Unal $\boldsymbol{e t}$ $\boldsymbol{a l} .^{(15)}$ injected BTX-A into the bilateral nasal mucosa in patients complaining of allergic rhinitis and showed that a single injection of BTX-A reduced nasal symptoms for up to two months. In addition, Yang et al. ${ }^{(\mathbf{1 6})}$ compared the therapeutic effects of BTX-A or steroids following injection into the inferior turbinates of patients. They concluded that BTX-A was more effective than steroids in relieving AR symptoms, especially for preventing nasal obstruction and rhinorrhea. Abtahi et al. ${ }^{\mathbf{1 7})}$ compared the consequences of BTX-A injection into the nasal septum and those into the inferior turbinate in AR patients. Both methods efficaciously decreased AR symptoms.

Rohrbach et $\boldsymbol{a l}_{\mathbf{.}^{(\mathbf{1 2})}}$ introduced BTX-A-soaked sponges to each nostril using bayonet forceps, which left in the nose for one hour. After exposure, a marked decrease in nasal secretions was observed. They concluded that such treatment is a minimally invasive and favorable for therapy of AR up to 3 months, even in patients with conventional therapy-resistant symptoms.

Abtahi et al. ${ }^{(17)}$ and Wen et al. ${ }^{(18)}$ reported that the effect of BTX-A on the nasal mucosa has been proposed in to be exerted through four feasible mechanisms: 1 . Suppression of acetylcholine release from the cholinergic nerve endings in the nasal mucosa, 2. From preganglionic cholinergic nerve endings in the sphenopalatine ganglion, 3. Induction of apoptosis of the nasal submucosal glands, and 4. Reducing the secretion of neuropeptides such as substance $\mathrm{p}$ from the trigeminal and parasympathetic nerve endings.

Subsequently, Ozcan and Ismi ${ }^{(19)}$ concluded that intranasal BTX-A administration through variable ways and doses seems to be an effective and secure option for controlling symptoms of allergic rhinitis, especially rhinorrhea, with a long-lasting action.

Concerning corticosteroids and antihistamines, Sánchez and Castro ${ }^{(20)}$ conducted a study comparing different antihistamine drugs to corticosteroids and combined preparations. Their results proved that there was no significant difference between groups at baseline regarding TNSS; while at the end of follow-up, the results 
were in favor with corticosteroids, although in all groups the score decreased significantly.

In addition, Brozek et $\boldsymbol{a l}^{(\mathbf{2 1})}$ reported that corticosteroids are superior for the control of nasal symptoms, which is why, in some studies, corticosteroids are encouraged over antihistamines.

Furthermore, Juel-Berg et $\boldsymbol{a l}_{.}{ }^{(22)}$ reported that, intranasal corticosteroids are superior to oral antihistamines regarding the control of AR symptoms and the improvement in the patient's QoL.

Devillier et $\boldsymbol{a l} .{ }^{(23)}$ pronounced that second generation antihistamines (e.g., Fexofenadine) had minimal or decreased sedative effects compared with first generation agents, a long-standing duration of action, and pharmacodynamics traits that permit once-daily dosing. Furthermore, Bachert ${ }^{(24)}$ concluded that antihistamine of second generation (e.g., desloratadine, fexofenadine, and levocetirizine) are effective in alleviation of the nasal congestion associated with AR when compared to placebo. They added, these agents are appropriate alternatives for the treatment of nasal symptoms in patients with AR.

\section{CONCLUSION AND RECOMMENDATION}

From the results of the current study, it can be concluded that BTX-A may be a reasonable alternate for the allergic rhinitis treatment, especially in those not respond to other medications. Otherwise, the conventional treatment with second generation antihistamine or corticosteroids is effective. Another wide scale studies on cost, patients compliance, long term effects and complications may be able to shift doctor and patient decision as regarding selecting treatment line.

\section{REFERENCES}

1. Pinar E, Eryigit O, Oncel S (2008): Efficacy of nasal corticosteroids alone or combined with antihistamines or montelukast in treatment of allergic rhinitis. Auris Nasus Larynx, 35: 61-66.

2. Okubo K, Kurono Y, Ichimura K, Enomoto T, Okamoto Y, Kawauchi H et al. (2017): Japanese guidelines for allergic rhinitis 2017. Allergol Int., 66: 205-219.

3. Bousquet J, Khaltaev N, Cruz AA, Denburg J, Fokkens WJ, Togias A et al. (2008): Allergic Rhinitis and its Impact on Asthma (ARIA) 2008. Allergy, 63(86): 158-160.

4. Richaed LM, Bradley FM (2010): Allergic rhinitis. In: Cummings Otolaryngology Head \& Neck Surgery. Cummings CW, Flint PW, Harker LA, Haughey BH, and Richardson MA. (Eds.), Elsevier Mosby (Publisher), Philadelphia, $4^{\text {th }}$ ed.

5. Bousquet J (2002): Quality of life in allergic rhinitis. Clin. Exp Allergy Rev., 2: 55-59.

6. Bousquet J, van Cauwenberge P, Khaltaev N (2001): Allergic rhinitis and its impact on asthma. J Allergy Clin Immunol., 108(5): S147-334.

7. Horak F, Stubner U, Zieglmayer R, Harris AG (2003): Comparison of the effects of desloratadine 5-mg daily and placebo on nasal airflow and seasonal allergic rhinitis symptoms induced by grass pollen exposure. Allergy, 58: 481485.

8. Meltzer EO (2002): Clinical evidence of antileukotriene therapy for allergic rhinitis. Ann Allergy Asthma Immunol., 88: 23-29.

9. Juniper EF, Riis B, Juniper BA (2007): Development and validation of an electronic version of the Rhinoconjunctivitis Quality of Life Questionnaire. Allergy, 62:1091-1093.

10. Aoishi K, Takahashi H, Hato N, Gyo K, Yokota M, Ozaki S, Suzuki M (2016): Treatment of allergic rhinitis with intranasal infusion of botulinum toxin type A. Life Sciences, 147: 132-136.

11. Burgen AS, Dickens F, Zatman LJ (1949): The action of botulinum toxin on the neuromuscular junction. J Physiol., 109: 10-24.

12. Rohrbach S, Junghans K, Köhler S, Laskawi R (2009): Minimally invasive application of botulinum toxin A in patients with idiopathic rhinitis. Head Face Med., 5: 18-24.

13. Jeon IK, Chang SK, Park GH, Roh MR (2013): Comparison of microneedle fractional radiofrequency therapy with intradermal botulinum toxin-A injection for periorbital rejuvenation. Dermatology, 227(4): 367-372.

14. Dorizas A, Krueger N, Sadick NS (2014): Aesthetic uses of the botulinum toxin. Dermatol Clin., 32(1): 23-36.

15. Unal M, Sevim S, Doğu O, Vayisoğlu Y, Kanik A (2003): Effect of botulinum toxin type-A on nasal symptoms in patients with allergic rhinitis: a double-blind, placebo controlled clinical trial. Acta Otolaryngol., 123: 1060-1063.

16. Yang TY, Jung YG, Kim YH, Jang TY (2008): A comparison of the effects of botulinum toxin A and steroid injection on nasal allergy. Otolaryngol Head Neck Surg., 139: 367-371.

17. Abtahi SM, Hashemi SM, Abtahi SH, Bastani B (2013): Septal injection in comparison with inferior turbinates injection of botulinum toxin A in patients with allergic rhinitis. J Res Med Sci., 18(5): 400-404.

18. Wen WD, Yuan F, Wang JL, Hou YP (2007): Botulinum toxin therapy in the ovalbumin-sensitized rats. Neuroimmunomodulation, 14: 78-83.

19. Ozcan C, Ismi O (2016): Botulinum Toxin for Rhinitis. Curr Allergy Asthma Rep., 16: 58-62.

20. Sánchez G, Castro C (2019): Prescription Profile and Clinical Outcomes in Patients with Allergic Rhinitis Treated with Oral Antihistamines or Nasal Corticosteroids. Int Arch Otorhinolaryngol., 23: e325-e330.

21. Brozek JL, Bousquet J, Baena-Cagnani CE et al. (2010): Allergic Rhinitis and its Impact on Asthma (ARIA) guidelines: 2010 revision. J Allergy Clin Immunol., 126(03):466-476.

22. Juel-Berg N, Darling P, Bolvig J et al. (2017): Intranasal corticosteroids compared with oral antihistamines in allergic rhinitis: a systematic review and meta-analysis. Am J Rhinol Allergy, 31(01): 19-28.

23. Devillier P, Roche N, Faisy C (2008): Clinical pharmacokinetics and pharmacodynamics of desloratadine, fexofenadine and levocetirizine. Clinical Pharmacokinetics, 47(4): 217-230.

24. Bachert C, Kuna P, Sanquer F et al. (2009): Comparison of the efficacy and safety of bilastine $20 \mathrm{mg} v s$ desloratadine $5 \mathrm{mg}$ in seasonal allergic rhinitis patients. Allergy, 64(1): 15865. 